\title{
Symptomatic Effects of Chest Physiotherapy with Increased Exhalation Technique in Outpatient Care for Infant Bronchiolitis: A Multicentre, Randomised, Controlled
} Study. Bronkilib 2

\author{
S. Sebban ${ }^{1}$, D. Evenou ${ }^{1}$, C. Jung ${ }^{2}$, C. Fausser ${ }^{1}$, S. JC. Jeulin ${ }^{3}$, S. Durand ${ }^{1}$, M. Bibal ${ }^{1}$, V. Geninasca ${ }^{1}$, M. Saux ${ }^{1}$, M. Leclerc ${ }^{4}$ \\ ${ }^{1}$ Association des Réseaux Bronchiolite, 48 Boulevard Sérurier, 75019 Paris, France \\ ${ }^{2}$ Centre de Recherche Clinique, Centre Hospitalier Intercommunal de Créteil, Service de Pédiatrie, Créteil, France \\ ${ }^{3}$ Réseau Bronchiolite Haute Savoie 8 avenue de Champ Fleuri 74600 Seynod, France \\ ${ }^{4}$ Réseau Bronchiolite Normand, Bois Guillaume Teaching Hospital,147 avenue du Maréchal Juin 76000 Rouen, France
}

*Corresponding author: D. Evenou, Association des Réseaux Bronchiolite, 48 Boulevard Sérurier, 75019 Paris, France; Email: devenou@orange.fr

Received: July 03, 2019; Accepted: July 17, 2019; Published: August 11, 2019;

\begin{abstract}
Objectives: The effectiveness of chest physiotherapy (CP) with increased exhalation technique (IET) to treat infants hospitalised for bronchiolitis has not to date been demonstrated. In outpatient settings, data are lacking to confirm CP's effectiveness. The purpose of our study was to assess the impact of $\mathrm{CP}$ in outpatient care for infants with bronchiolitis.

Methods: We conducted a multicentre, randomized, controlled, single-blind study involving infants under 12 months treated on an outpatient basis. The primary endpoint, a decrease in the severity classification level of the infants' respiratory difficulties, was compared between two patient groups, one with and one without $\mathrm{CP}$.

A total of 82 infants were randomized; 41 were assigned to the CP group and 41 to the control group. Different blinded assessors determined the Wang Clinical Severity Score at inclusion (T0) and 30 minutes after inclusion (T1) for each group.

Results: In the group that received CP, 29 infants (70.7\%) showed improvement and their severity level was modified, as compared to 4 (9.76\%) in the control group $(\mathrm{p}<0.001)$. The mean decrease in the Wang Clinical Severity Score was: $-2( \pm 1.32)$ in the group receiving physiotherapy compared to -0.22 $( \pm 0.99)$ in the control group $(\mathrm{p}<0.001)$.
\end{abstract}

Conclusions: Our study results suggest a symptomatic effect of CP with IET for short-term clinical improvement among infants with bronchiolitis in outpatient settings.

Keywords: bronchiolitis, infants, chest physiotherapy

\section{Introduction}

Infant bronchiolitis is a common disease that causes a large number of patients to seek outpatient medical and physiotherapy care in France. Numerous studies and international recommendations $[1,2,3]$ have indicated that no drug is effective in care for bronchiolitis. In September 2000, a consensus conference sponsored by the French National Agency for Health Accreditation and Evaluation (ANAES) reached the same conclusion [4].

With respect to chest physiotherapy $(\mathrm{CP})$, postural drainage therapy, vibration and conventional chest physiotherapy (CPT) are not considered to be effective $[5,6]$. Although the ANAES has recommended the utilization of chest physiotherapy with prolonged slow expiration techniques combined with assisted coughing [4], there is little proof of its effectiveness (grade C). For this reason, the ANAES has advocated that studies be conducted in "outpatient" settings to assess CP's degree of effectiveness.

Much more recently, a Cochrane Review publication recommended exploring the effects of $\mathrm{CP}$ techniques among mild to moderate nonhospitalised patients [6]. In fact, most of the studies conducted to date have focused exclusively on infants who were hospitalised for severe bronchiolitis. For this type of patient group, the effectiveness of such treatment, aiming to reduce time to recovery, has not been demonstrated $[7,8]$. However, three recently conducted studies have produced new data $[9,10,11]$. Despite the inherent limitations of the methodologies used and/or the number of subjects, these studies once again raise the question of the effectiveness of CP combined with IET in outpatient settings. For this reason, we undertook to assess the symptomatic effect of $\mathrm{CP}$ as a component of outpatient care for infant bronchiolitis, in line with recommendations in France. 


\section{Materials and methods}

\subsection{Study design and organisation}

We conducted a multicentre, randomized, controlled, single blind study comparing a group of infants receiving physiotherapy and a control group without physiotherapy. For our study, children were enrolled at four centres: two located in the Ile de France region, one located in Normandy, and one located in the Auvergne Rhône Alpes region of France. The study was conducted during an acute bronchiolitis epidemic season between 17 December 2016 and 01 February 2017.

Upon the recommendation of the ethical committee of Robert Debré University Paediatric Hospital Centre, we submitted our study to a French institutional review board, the Comité de Protection des Personnes CPP IV IDF (ID-RCB n²016-A01553-48), which approved the study at its meeting of 22 November 2016. In addition, our clinical trial was registered with the French National Agency for Medicines and Health Products Safety (ANSM) and assigned No. ID-RCB 2016A01553-48. Lastly, we submitted a declaration of compliance with a reference methodology to the French Data Protection Authority (CNIL), and we provided an information sheet to parents of infants taking part in the study. We obtained the oral consent and nonopposition of all the parents of children who participated in the study.

\subsection{Participants}

To be included in the study, infants had to be between one and 12 months old [12] and experiencing a first or second episode of bronchiolitis for which their GP had prescribed outpatient CP (the first or second session of CP for this episode). Only infants who had been assigned a Wang Clinical Severity Score $\geq 4$ and $<9$ were randomised after inclusion. Exclusion criteria included infants who had been born prematurely, i.e., before 34 weeks' gestation. Those with a history of bronchopulmonary dysplasia and serious pulmonary or cardiac disease were also excluded. In addition, infants presenting a contraindication to CP with IET (prolonged corticosteroid therapy, rickets, osteogenesis imperfecta or rib fracture) were not enrolled in the study.

\subsection{Randomisation, arms}

We used an on-line system (PHP/MySQL) for randomisation into blocks, centralised and stratified by centre, which we accessed using a login name and password. When authorized investigators connected to the system to enrol a patient, they checked to ensure that inclusion criteria had been met and no exclusion criteria were present.

A stratification by centre approach ensured minimal imbalance among groups within the same study centre. Finally, so as to avoid any selection bias in relation to a specific centre, we imposed an upper limit of 40 patients per centre. We used a 1: 1 allocation with set blocks of 4. Study participants were randomised to receive $\mathrm{CP}$ immediately (Group A) or to receive CP later (Group B, the control group). For Group A, the Wang Clinical Severity Score was measured 30 minutes after the CP session, while for Group B the Wang Score measured at 30 minutes was assessed before the $\mathrm{CP}$ session.

\subsection{Conduct of the study}

After informing the parents and obtaining their consent, the physiotherapist/investigator enrolled the infants meeting the inclusion criteria in the study (Figure 1).Wang Clinical Severity Scores were measured at inclusion (T0) and 30 minutes after inclusion (T1) by two different blinded assessors. Concerning infants participating in the study arm with $\mathrm{CP}$, a procedure was set up to ensure that the assessor would not know which randomisation arm infants were assigned to. Moreover, parents were told that verbal contact with the assessors would not possible. Only the physiotherapist/investigator who enrolled the child in the study and the physiotherapist who performed the $\mathrm{CP}$ with IET on infants in the $\mathrm{CP}$ randomisation arm (obtained by entering the initials and the randomisation site) knew which arm children had been assigned to. We developed this two-step, independent Wang Clinical Severity Score evaluation procedure to avoid any observer bias while relying on the satisfactory inter-observer reproducibility of the score assessment $[13,14,15]$ and its utilisation for studies involving hospitalised infants [16,17]. We followed our usual standard of care and all the infants who participated in the study received CP with IET.

\subsection{Intervention}

All the physiotherapists/investigators in our study received training to comply with the standardisation of professional practice requirements and to ensure the reproducibility of the techniques. Chest physiotherapy as performed during this study involves a passive technique designed to produce sufficient airflow to generate air-mucus interaction. Passive expiration is produced through manual thoracicabdominal pressure while respecting the mechanical rotational axis shared by the costovertebral and costotransverse joints. Two clinical indicators are used to check expiratory airflow: an audible indicator (an increase in wet or productive coughing sounds) and a tactile indicator (vibrations under the hand on the thorax) [18]. These two indicators guide the physiotherapist's movements during CP. Because the anatomy of infants' lower respiratory tract is associated with poor pulmonary compliance, it is important to carefully control the movements with each expiration in order to obtain a continuous flow without ever causing the collapse [4] of the peripheral bronchial structure. As long as the flow is audible from the infant's mouth and the expiratory movement can be performed, there is no collapse [18]. Under these quality and safety conditions, this technique aims to produce drainage of the secretions and to reduce the obstructive syndrome related to congestion. The techniques used within the scope of the study did not require practising deliberate movements to assist coughing.

\subsection{Primary endpoint}

Our primary endpoint was comparing the number of responsive patients in each group. A responsive patient was defined as an infant whose Wang Clinical Severity Score decreased between the first and second assessment [19]. For the purposes of monitoring symptoms in an outpatient setting, this is a more significant occurrence than a simple variation in score. The Wang Clinical Severity Score [13] 
D. Evenou (2019) Symptomatic Effects of Chest Physiotherapy with Increased Exhalation Technique in Outpatient Care for Infant Bronchiolitis: A Multicentre, Randomised, Controlled Study. Bronkilib 2

measures the degree of breathing difficulty (Table 1). A total score of less than or equal to $3 / 12$ is interpreted as benign bronchiolitis, from 4 to $8 / 12$ as moderate bronchiolitis, and 9/12 or more as severe bronchiolitis [19]. The scores were determined by blinded assessors who did not know to which group the patient had been assigned during randomisation.

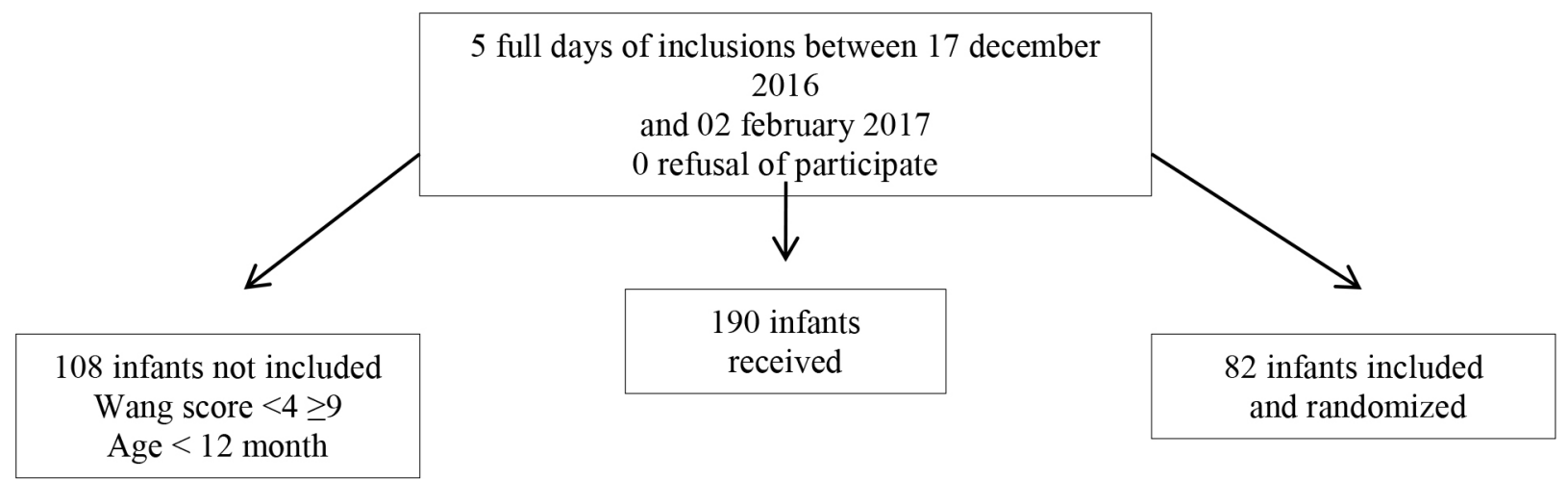

Figure 1. Flow chart

Table 1. Wang Score definition

\begin{tabular}{|l|c|c|c|c|}
\hline & & $\mathbf{1}$ & Score \\
\cline { 2 - 5 } & $\mathbf{0}$ & $31-45$ & $\mathbf{2}$ \\
\hline Respiratory rate (breaths/min) & $<30$ & None & $\begin{array}{c}\text { Terminal expiratory or only with } \\
\text { stethoscope }\end{array}$ & $\begin{array}{c}\text { Entire expiration or audible during expiration } \\
\text { without stethoscope }\end{array}$ \\
\hline Wheezing & None & Intercostal only & Trachcostcmal \\
\hline Retractions & Normal & - & Severe with nasal flaring \\
\hline General condition & & & Irritable, lethargic, poor feeding \\
\hline
\end{tabular}

\subsection{Secondary endpoints}

- Changes in the Wang Clinical Severity Score assessed at T0 and at $\mathrm{T} 1$ after randomisation of each group.

- CP tolerance among patients in Group A, based on events reported during chest physiotherapy: discomfort, vomiting, pain, worsening of the child's condition.

\subsection{Collected data}

Collected data concerned, among other information: the identification of an atopic predisposition [20, 21], the infant's age, concomitant treatment, and data recorded by the investigator physiotherapist in the electronic case report form developed for the purpose of the study.

\subsection{Statistical analyses}

For qualitative variables, absolute values and percentages were used. For quantitative variables, mean and standard deviation were used. Comparisons between the two groups were made using the Chisquare test, Fischer's exact test, Student's $t$-test or the Wilcoxon and Mann-Whitney tests, depending on the type and distribution of the variables. Matched data sets before and after care were analysed using paired Student's $t$-tests or McNemar's test, depending on the type of data.
The significance level was $\mathrm{P}<0.05$. STATA v13.1 software (Stata Corporation, College Station, Texas, USA) was used for statistical analyses.

\section{Results}

\subsection{Description of the study population}

During the study period, we saw 190 infants in 4 centres (Figure 2). A total of 82 infants were included in the study, 41 in the group receiving chest physiotherapy (Group A) and 41 in the control group (Group B). The patient population within each group was comparable in terms of age and gender. The mean patient age was 204.8 days $( \pm 82.4)$ in Group A and 218 days $( \pm 81)$ in Group B.

There were more male than female infants in Group A (61\%) and in Group B (56.1\%). With respect to other demographic characteristics collected at inclusion, statistical tests revealed no difference in distribution (Table 2). In addition, there was no significant difference between the two groups with respect to the amount of time (number of days) the disease evolved after the randomisation.

\subsection{Results}

At the end of the first CP session, 29 infants (70.7\%) in Group A were responsive to $\mathrm{CP}$ with IET as reflected in a change in the severity 
D. Evenou (2019) Symptomatic Effects of Chest Physiotherapy with Increased Exhalation Technique in Outpatient Care for Infant Bronchiolitis: A Multicentre, Randomised, Controlled Study. Bronkilib 2

classification level of their condition, compared to 4 infants (9.76\%) in the control group $(\mathrm{p}<0.001)$ (Table 3). The results of Wang Clinical Severity Score (secondary endpoint) at T0 and T1 also changed significantly between the 2 groups. In Group A, they went from 4.83
$( \pm 0.86)$ to $2.83( \pm 1.16)$ and in Group B they went from $4.83( \pm 0.99)$ to $4.61( \pm 1.18)$ (Table 2$)$. The mean decrease in the score was $-2( \pm 1.32)$, $-2[-5 ; 0]$ in Group A compared to $-0.22( \pm 0.99), 0[-3 ; 1]$ in Group B $(\mathrm{p}<0.001)$ (Table 2).

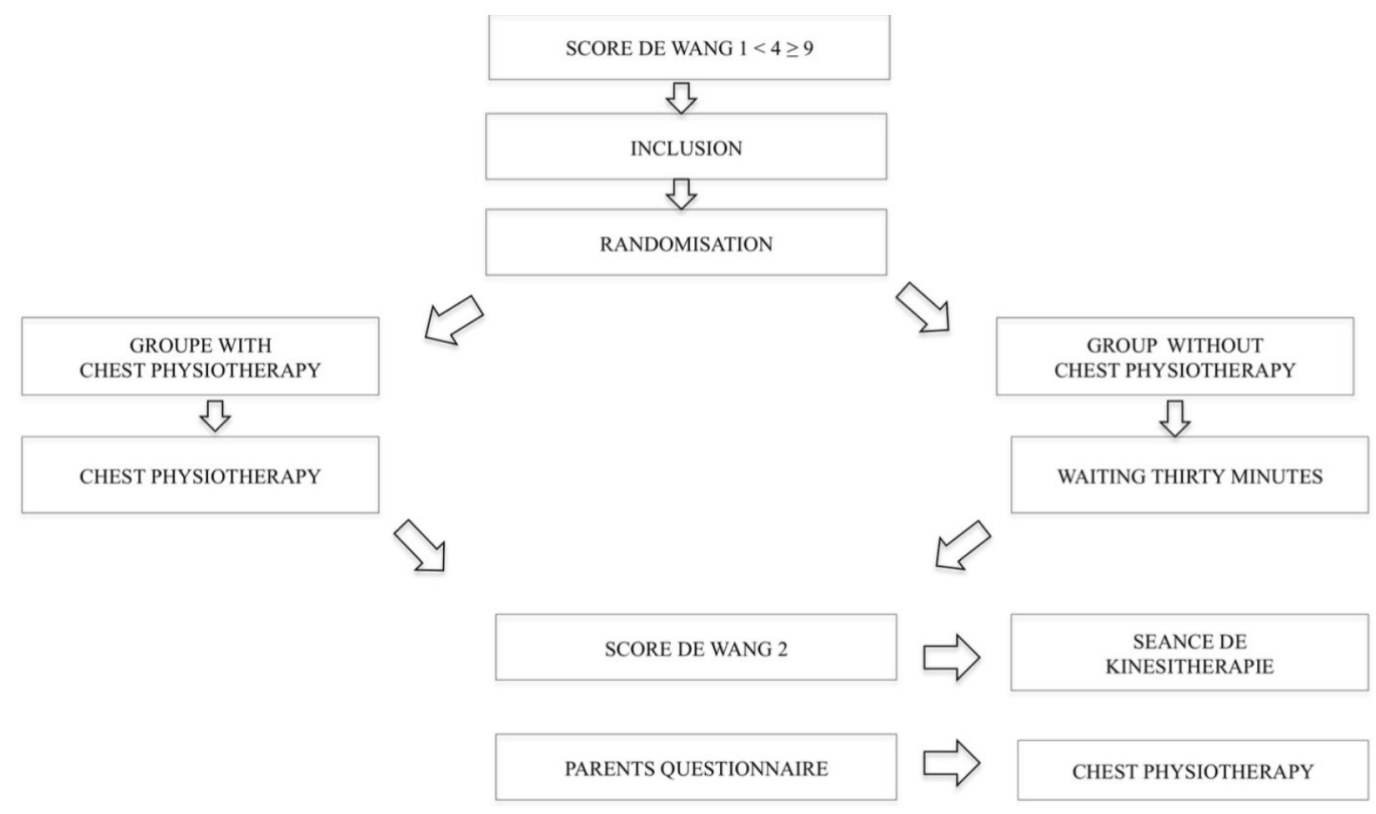

Figure 2. Study design

Table 2. Characteristics of the study population

\begin{tabular}{|c|c|c|c|}
\hline Item & $\begin{array}{c}\text { GROUPA } \\
\text { chest physiotherapy } \\
\qquad \mathbf{N}=\mathbf{4 1}\end{array}$ & $\begin{array}{c}\text { GROUP B } \\
\text { not chest physiotherapy } \\
\mathbf{N}=\mathbf{4 1}\end{array}$ & $\mathbf{P}$ \\
\hline Age in days & $204.8( \pm 82.4), 198[55 ; 363]$ & $218( \pm 81), 219[79 ; 364]$ & $0.47 *$ \\
\hline Sex (Male) & $25(61 \%)$ & $23(56.1 \%)$ & $0.65 * *$ \\
\hline Family history of asthma & $10(24.4 \%)$ & $16(39 \%)$ & $0.15 * *$ \\
\hline History of eczema & $3(7.3 \%)$ & $5(12.2 \%)$ & $0.71 * * *$ \\
\hline No treatment & $15(36.6 \%)$ & $18(43.9 \%)$ & $0.50 * *$ \\
\hline Antibiotic treatment & $10(24.4 \%)$ & $7(17.1 \%)$ & $0.41 * *$ \\
\hline Bronchodilator treatment & $21(51.2 \%)$ & $20(48.8 \%)$ & $0.83 * *$ \\
\hline Corticosteroid treatment & $7(17.1 \%)$ & $11(26.8 \%)$ & $0.29 * *$ \\
\hline Antitussive treatment & $1(2.4 \%)$ & $1(2.4 \%)$ & $1.00 * * *$ \\
\hline \multirow{2}{*}{$\begin{array}{l}\text { Delay between the symptoms } \\
\text { and the session }\end{array}$} & \multirow[t]{2}{*}{$7.9( \pm 7.1), 6[1 ; 29]$} & \multirow[t]{2}{*}{$4.8( \pm 3.4), 4[1 ; 17]$} & $0.01 *$ \\
\hline & & & $0.03 * * * *$ \\
\hline
\end{tabular}

* Student, $* * \chi^{2}, * * *$ Exact de Fisher, **** Wilcoxon-Mann-Whitney

Table 3. Evolution of the Wang Clinical Severity Score in Group A and Group B

\begin{tabular}{|c|c|c|c|c|c|c|}
\hline & \multicolumn{3}{|c|}{ First assesment } & \multicolumn{3}{|c|}{ Second assesment } \\
\hline$* *$ Student & $\begin{array}{c}\text { Group A } \\
\mathbf{N}=\mathbf{4 1}\end{array}$ & $\begin{array}{c}\text { Group B } \\
\mathbf{N}=\mathbf{4 1}\end{array}$ & $\mathbf{P} * *$ & $\begin{array}{c}\text { Group A } \\
\mathbf{N}=41\end{array}$ & $\begin{array}{c}\text { Group B } \\
\mathbf{N}=\mathbf{4 1}\end{array}$ & $\mathbf{P} * *$ \\
\hline Wang Respiratory Scores values & $4,83( \pm 0,86), 5[4 ; 7]$ & $4,83( \pm 0,99), 5[4 ; 8]$ & 1 & $2,83( \pm 1,16), 3[1 ; 6]$ & $4,61( \pm 1,18), 4[2 ; 8]$ & $<0,001$ \\
\hline
\end{tabular}


Table 4. Comparing the decrease in clinical severity scores, Group A and Group B

\begin{tabular}{|c|c|c|c|c|c|c|c|c|}
\hline & \multicolumn{2}{|c|}{$\begin{array}{c}\text { GROUPA } \\
\text { chest physiotherapy }\end{array}$} & \multirow{2}{*}{$\begin{array}{c}\mathrm{N}=41 \\
\text {-12 (\%) }\end{array}$} & & \multicolumn{2}{|c|}{ GROUP B } & \multirow{2}{*}{$\begin{array}{c}\mathrm{N}=41 \\
9-12(\%)\end{array}$} & \multirow[b]{2}{*}{$\mathbf{P}$} \\
\hline & 0-3 (\%) & 4-8 (\%) & & & 0-3 (\%) & 4-8 (\%) & & \\
\hline $0-3$ & $0(0,0)$ & $0(0,0)$ & $0(0,0)$ & $0-3$ & $0(0,0)$ & $0(0,0)$ & $0(0,0)$ & \\
\hline $4-8$ & $29(70,7 \%)$ & $12(29,3 \%)$ & $0(0,0)$ & $4-8$ & $4(9,76 \%)$ & $37(90,24 \%)$ & $0(0,0)$ & $<0,001 * * *$ \\
\hline $9-12$ & $0(0,0)$ & $0(0,0)$ & $0(0,0)$ & $9-12$ & $0(0,0)$ & $0(0,0)$ & $0(0,0)$ & \\
\hline
\end{tabular}

\subsubsection{Differences between the groups in terms of Wang Score criteria}

The Wang Clinical Severity Score items that were most impacted in Group A between T0 and T1 were respiratory rate and wheezing (Table 5).

\subsubsection{Monitoring undesirable side effects}

No undesirable side effects were reported among the infants in Group A during the study.

\section{Discussion}

The effects of chest physiotherapy (CP) with increase exhalation technique (IET) for respiratory difficulties had not been studied up to now using a randomised approach with a control group in an outpatient setting. Ours was thus a first study conducted within the context of real-life infant bronchiolitis primarily targeting a clinical objective (change in the severity level). While the study required the involvement of a large number of healthcare professionals, this did not limit its feasibility nor its acceptability. In fact, it was thus possible to recruit a sufficient number of infants in each group while limiting observer bias, given that the assessors were independent and were not the same as the physiotherapists providing CP. Our study population's gender and age (under 12 months) were representative of infants with bronchiolitis as described in the literature $[4,12]$. This study population requires outpatient care, since we excluded from the study any infants with very severe conditions (Wang Score >9) who needed to be hospitalised.

Our findings highlight a significant change in the initial severity classification level of the infants receiving care, with the severity level decreasing between the first and the second evaluation (Table 4). The data was corroborated by changes in the Wang Clinical Severity Score (Table 3). We chose to use this score [13] as our secondary endpoint based on its inter-observer reproducibility, which is moderate according to Landis and Koch classification (Kappa=0.48) [14]. Moreover, this score has been used several times in studies to assess the effects of CP $[16,17]$.

Given the characteristics of the study population, the clinical improvement we observed appears to be statistically unrelated to age at the first session, the presence of an atopy or treatment with prescribed drugs, whether or not it is adhered to (Table 2). It appears to indicate that practicing $\mathrm{CP}$ with IET has an effect on the short-term progress of the respiratory difficulty parameters observed in bronchiolitis. If we limit ourselves to the increased exhalation technique (IET) alone, it could impact the bronchial (airway) tree hydrodynamic resistance caused by overproduction of secretions [22], one of the three causes of obstruction in bronchiolitis, along with inflammation and the possible role of bronchial hyper reactivity [23]. This could explain the observed control over the course of the disease in the short term, based on the items in the Wang Clinical Severity Score (respiratory rate, wheezing), with as a corollary, the study populations tending to move toward less severe scores.

A discussion of our findings would nevertheless not be complete without mentioning factors that study participants may have been exposed to but which were not included or evaluated as part of our study, and whose impact cannot be measured - such as, for some infants, the use of induced coughing manoeuvres that may have impacted the results. Yet the purpose of this clinical study was to assess the practice of IET alone; spontaneous coughing, which occurs naturally as part of the disease, is not sufficient alone to limit a patient's symptoms given its weak "efficacy" [24]. A future protocol that studies an "induced cough" group independently would make it possible to detect a possible causal relationship. In another area, a potential "care provider" effect seems to be possible. Reported recently, this effect has a positive impact on the occurrence of respiratory tract infections in the medium to long term [25]. The design of our study allowed only the quantification of short-term effects, and it is unlikely that effects related to the care provider could be observed in such a short amount of time.

The data from our study did not provide an indication of the potential long-term effects of the care that was provided. To address this question, we collected data about the infants' subsequent progress by submitting a questionnaire to their parents 7 days after the CP. According to survey respondents $(n=52), 25 \%$ of the infants saw a doctor, $8 \%$ were taken to the paediatric emergency department, and one infant required hospitalisation. In addition, it is worth noting that the absence of reported undesirable side effects in the study appears to confirm the observations of two studies in the Cochrane Review [6]. The potential occurrence of undesirable side effects in the study population must also be considered. Ambulatory patients with moderate bronchiolitis are naturally less at risk than hospitalized patients, who may be younger and may present more severe forms 
D. Evenou (2019) Symptomatic Effects of Chest Physiotherapy with Increased Exhalation Technique in Outpatient Care for Infant Bronchiolitis: A Multicentre, Randomised, Controlled Study. Bronkilib 2

of bronchiolitis. For these patients, it would be reasonable to carry out a benefit/risk analysis before considering this type of care. Lastly, a word about care management: Although to date there have been few arguments to justify the level of prescriptions for outpatient CR with IET in France [26], the immediate decrease in the severity of respiratory difficulty observed in our study may explain this practice, initially based on expert opinion and the observation of considerable clinical improvement [4].

Tableau 5. Variation in items on Wang Score between $\mathrm{T} 0$ and T, Group A and Group B

\begin{tabular}{|c|c|c|c|c|c|c|}
\hline \multirow[b]{2}{*}{ Item } & \multicolumn{3}{|c|}{ Wang T0 } & \multicolumn{3}{|c|}{ Wang T1 } \\
\hline & $\begin{array}{c}\text { Group A T0 } \\
\mathbf{N}=41\end{array}$ & $\begin{array}{c}\text { Group B T0 } \\
\qquad N=41\end{array}$ & $\mathbf{P}$ & $\begin{array}{c}\text { Group A T1 } \\
\mathrm{N}=41\end{array}$ & $\begin{array}{c}\text { Group B T1 } \\
\mathbf{N}=41\end{array}$ & $\mathbf{P}$ \\
\hline Wang Score & & & 0,630 & & & 0,000 \\
\hline 1 & $0(0 \%)$ & $0(0 \%)$ & & $5(12,2 \%)$ & $0(0 \%)$ & \\
\hline 2 & $0(0 \%)$ & $0(0 \%)$ & & $12(29,3 \%)$ & $2(4,9 \%)$ & \\
\hline 3 & $0(0 \%)$ & $0(0 \%)$ & & $12(29,3 \%)$ & $2(4,9 \%)$ & \\
\hline 4 & $17(41,5 \%)$ & $20(48,8 \%)$ & & $10(24,4 \%)$ & $17(41,5 \%)$ & \\
\hline 5 & $16(39 \%)$ & $11(26,8 \%)$ & & $1(2,4 \%)$ & $12(29,3 \%)$ & \\
\hline 6 & $6(14,6 \%)$ & $8(19,5 \%)$ & & $1(2,4 \%)$ & $6(14,6 \%)$ & \\
\hline 7 & $2(4,9 \%)$ & $1(2,4 \%)$ & & $0(0 \%)$ & $1(2,4 \%)$ & \\
\hline 8 & $0(0 \%)$ & $1(2,4 \%)$ & & $0(0 \%)$ & $1(2,4 \%)$ & \\
\hline Respiratory rate (breaths/min) & & & 0,239 & & & 0,000 \\
\hline 0 & $1(2,4 \%)$ & $0(0 \%)$ & & $26(63,4 \%)$ & $10(24,4 \%)$ & \\
\hline 1 & $9(22 \%)$ & $12(29,3 \%)$ & & $15(36,6 \%)$ & $26(63,4 \%)$ & \\
\hline 2 & $29(70,7 \%)$ & $23(56,1 \%)$ & & $0(0 \%)$ & $5(12,2 \%)$ & \\
\hline 3 & $2(4,9 \%)$ & $6(14,6 \%)$ & & $0(0 \%)$ & $0(0 \%)$ & \\
\hline & & & 0,128 & & $0(0 \%)$ & 0,003 \\
\hline 0 & $4(9,8 \%)$ & $1(2,4 \%)$ & & $19(46,3 \%)$ & $6(14,6 \%)$ & \\
\hline 1 & $13(31,7 \%)$ & $21(51,2 \%)$ & & $14(34,2 \%)$ & $16(39 \%)$ & \\
\hline 2 & $22(53,7 \%)$ & $19(46,3 \%)$ & & $8(19,5 \%)$ & $19(46,3 \%)$ & \\
\hline 3 & $2(4,9 \%)$ & $0(0 \%)$ & & $0(0 \%)$ & $0(0 \%)$ & \\
\hline Retractions & & & 0,054 & & & 0,005 \\
\hline 0 & $5(12,2 \%)$ & $0(0 \%)$ & & $18(43,9 \%)$ & $5(12,2 \%)$ & \\
\hline 1 & $16(39 \%)$ & $22(53,7 \%)$ & & $14(34,2 \%)$ & $19(46,3 \%)$ & \\
\hline 2 & $20(48,7 \%)$ & $19(46,3 \%)$ & & $9(22 \%)$ & $17(41,5 \%)$ & \\
\hline 3 & $0(0 \%)$ & $0(0 \%)$ & & $0(0 \%)$ & $0(0 \%)$ & \\
\hline General condition & & & 1,000 & & & 0,494 \\
\hline 0 & $39(95,1 \%)$ & $39(95,1 \%)$ & & $41(100 \%)$ & $39(95,1 \%)$ & \\
\hline 3 & $2(4,9 \%)$ & $2(4,9 \%)$ & & $0(0 \%)$ & $2(4,9 \%)$ & \\
\hline
\end{tabular}




\section{Conclusion}

Several authors have called for a randomised, controlled study of infants with bronchiolitis in an outpatient setting $[8,25]$. Based on our findings, this first study contributes to changing perceptions of the value of chest physiotherapy (CP) with increase exhalation technique (IET) for this indication [25]. The observed clinical improvement, confirmed by a change in the immediate severity score, may reflect the impact on the short-term improvement of respiratory parameters of care provision based on CP with IET. This is in addition to the recognized role of the physiotherapist in monitoring the child's condition and providing information and guidance to families [12]. Subsequent studies could usefully focus on correlating this symptomatic effect with improvements in the infants' comfort, sleeping and feeding within the scope of a new qualitative study.

\section{Acknowledgments}

The authors would like to thank all the infants who participated in the study as well as their parents and all the physiotherapists who took part in the children's enrolment and care.

We would also like to thank the Clinical Research Centre (CRC) of the Créteil Inter communal Hospital Centre for providing methodological support, and ACTIV (Association Clinique Thérapeutique Infantile du Val de Marne), C. Levy and S. Bechet for data management and statistical processing.

\section{Competing interests}

The authors declare that they have no competing interests

Declaration of Interest: Conflicts of interest: none.

\section{Abbreviations}

ANAES: French National Agency for Health

ANSM: French National Agency for Medicines and Health Products Safety

APHP: Paris Pubic Hospitals Group

CHU: teaching hospital

CNIL: French Data Protection Authority

CP: chest physiotherapy

CPP: Committee for the Protection of Persons (ethics committee)

CRC: centre for clinical research

IDF: Ile de France Region (it includes the city of Paris and the surrounding area)

IET: increased exhalation technique

\section{References}

1. National Institute for Health and Care Excellence NICE. Bronchiolitis in children: diagnosis and management. NICE Guideline Juin 2015

2. Subcommittee on Diagnosis and Management of Bronchiolitis. Diagnosis and Management of Bronchiolitis. Pediatrics 2006 October 1, 2006; 118(4): 1774-93.

3. Ralston SL, Allan S, Lieberthal H Meissner HC and al. Clinical practice guideline: the diagnosis, management, and prevention of bronchiolitis. Pediatrics 2014; 134: e1474-e1502

4. Conférence de consensus prise en charge de la bronchiolite du nourrisson. Texte du consensus Anaes 2000.Sept 20
5. Bohe L, Ferrero ME, Cuestas E, Polliotto L and al Indications of conventional chest physiotherapy in acute bronchiolitis. Medicina 2004; 64 (3): 198-200.

6. Roqué I, Figuls M, Giné-Garriga M, Granados Rugeles C and al Chest physiotherapy for acute bronchiolitis in paediatric patients between 0 and 24 months old. Cochrane Database Syst Rev. 2016 Feb 1; 2: CD004873

7. Rochat I, Leis $\mathrm{P}$, Bouchardy $\mathrm{M}$, Oberli $\mathrm{C}$ and al. Chest physiotherapy using passive expiratory techniques does not reduce bronchiolitis severity: a randomized controlled trial. Eur J Pediatr. 2012 Mar; 171 (3): 457-62.

8. Gajdos V, Katsahian S, Beydon N, Abadie V and al. Effectiveness of chest physiotherapy in infants hospitalized with acute bronchiolitis: a multicenter, randomized, controlled trial. PLoS Med 2010; 7(9): e1000345.

9. Van Ginderdeuren F, Vandenplas Y, Deneyer M,Vanlaethem S and al. Effectiveness of Airway Clearance Techniques in Children Hospitalized With Acute Bronchiolitis Pediatric Pulmonology 2017; 52: 225-231

10. Evenou D, Sebban S, Fausser C, Girard D Evaluation de l'effet de la kinésithérapie respiratoire avec augmentation du flux expiratoire dans la prise en charge de la première bronchiolite du nourrisson en ville. Kinesither Rev 2017; 17(187): 3-8,

11. Sebban S, Pull L, Smail A, Menier I and al Influence of chest physiotherapy on the decision of hospitalization of the infant with acute bronchiolitis in a pediatric emergencies department. Kinesither Rev 2017;

12. Verstraete M, Cros P, Gouin M, H. Oillic and al. Prise en charge de la bronchiolite aiguë du nourrisson de moins de 1 an: actualisation et consensus médical au sein des hôpitaux universitaires du Grand Ouest (HUGO). Arch Pédiatr. 2014; 21(1): 53-62. 17 (183): 3-8.

13. Wang EE, Milner RA, Navas L, Maj H. Observer agreement for respiratory signs and oximetry in infants hospitalized with lower respiratory infections. Am Rev Respir Dis. 1992; 145: 106-9

14. Landis J.R., Koch G.G.: The Measurement of Observer Agreement for Categorical Data, Biometrics, 1977a, 33, 159-174.

15. Gajdos V, Beydon N, Bommenel L, Pellegrino B and al. Inter-observer agreement between physicians, nurses, and respiratory therapists for respiratory clinical evaluation in bronchiolitis. Pediatr Pulmonol. 2009 Aug; 44(8): 754-62.

16. Postiaux G, Louis J, Labasse HC, Gerroldt J and al. Effects of an alternative chest physiotherapy regimen protocol in infants with RSV bronchiolitis. Respiratory Care 2011; 56(7): 989-94. [DOI: 10.4187/respcare.00721; PUBMED: 21352671]

17. Gomes EL, Postiaux G, Medeiros DR, Monteiro KK and al. Chest physical therapy is effective in reducing the clinical score in bronchiolitis: randomized controlled trial [A fisioterapia respiratória é eficaz na redução de escore clínico na bronquiolite: ensaio controlado randomizado]. Revista Brasileira de Fisioterapia 2012; 16: 241-7.

18. Jeulin JC (2014) Approche Anthropologique du développement des compétences des masseurs-kinésithérapeutes. Conception d'un environnement informatique pour l'apprentissage en masso-kinésitherapie, Doctorat en Sciences de 1 'Education, université de Provence Aix Marseille, en ligne.

19. Postiaux G, Zwaenepoel B, Louis J. Chest physical therapy in Acute viral bronchiolitis. An updated review. Resp Care 2013; 58: 1541-5.

20. Zedan M, Gamil N, El Assmy M, Fayez E and al A Montelukast as an episodic modifier for acute viral bronchiolitis a randomized trial. Allergy Asthma Proc. 2010; 31 (2): 147-53

21. Castro-Rodriguez JA, Wright AL, Holberg CJ, Martinez FD and al A Clinical Index to Define Risk of Asthma in Young Children with Recurrent Wheezing, American Journal of Respiratory and Critical Care Medicine, Vol. 162, No. 4 (2000), pp. 1403-1406.

22. Mauroy B, Pelca D, Fausser C, Merckx J and al Toward the modeling of mucus draining from human lung: role of airways deformation on air-mucus interaction. Physical biology, 2011

23. Cody Meissner H, Viral Bronchiolitis in Children. N Engl J Med 2016; 374: 62-72 January 7, 2016

24. Ecoffey C, Hamza J, Meistelman C, Physiologie respiratoire du nourrisson. Anesthésiologie pédiatrique 1997

25. Alexandrino AS, Santos R, Melo C, Bastos JM and al. Caregivers' education vs rhinopharyngeal clearance in children with upper respiratory infections: impact on children's health outcomes. Eur J Pediatr 2017; 363: 1-9.

26. Joud P, Fetouh M, Billet D, Pierre B and al. La kinésithérapie est-elle toujours la pierre angulaire du traitement? Arch Pédiatr 2014; 21: 228-229

Citation:

S. Sebban, D. Evenou, C. Jung, C. Fausser, S. JC. Jeulin, S. Durand, M. Bibal, V. Geninasca, M. Saux, M. Leclerc (2019) Symptomatic Effects of Chest Physiotherapy with Increased Exhalation Technique in Outpatient Care for Infant Bronchiolitis: A Multicentre, Randomised, Controlled Study. Bronkilib 2. $J$ Clin Res Med Volume 2(4): 1-7. 